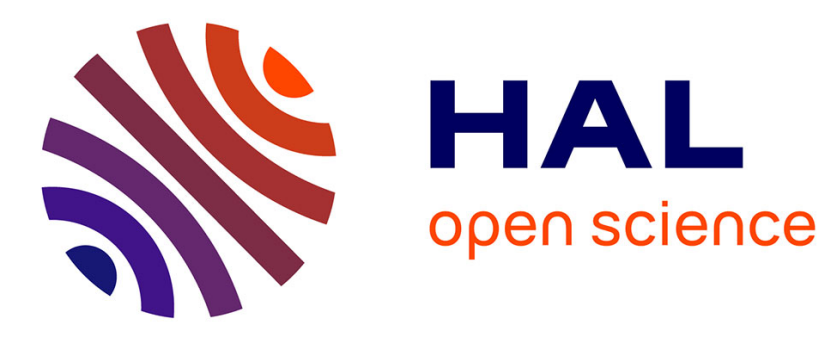

\title{
A Flexible Method for Covalent Double Functionalization of Graphene Oxide
}

Shi Guo, Yuta Nishina, Alberto Bianco, Cécilia Ménard-moyon

\section{To cite this version:}

Shi Guo, Yuta Nishina, Alberto Bianco, Cécilia Ménard-moyon. A Flexible Method for Covalent Double Functionalization of Graphene Oxide. Angewandte Chemie International Edition, 2020, 59 (4), pp.1542-1547. 10.1002/anie.201913461 . hal-02994627

\section{HAL Id: hal-02994627 https://hal.science/hal-02994627}

Submitted on 12 Nov 2020

HAL is a multi-disciplinary open access archive for the deposit and dissemination of scientific research documents, whether they are published or not. The documents may come from teaching and research institutions in France or abroad, or from public or private research centers.
L'archive ouverte pluridisciplinaire HAL, est destinée au dépôt et à la diffusion de documents scientifiques de niveau recherche, publiés ou non, émanant des établissements d'enseignement et de recherche français ou étrangers, des laboratoires publics ou privés. 


\title{
A Flexible Method for the Covalent Double Functionalization of Graphene Oxide
}

\author{
Shi Guo, ${ }^{a}$ Yuta Nishina, ${ }^{b, c}$ Alberto Bianco, ${ }^{a, *}$ and Cécilia Ménard-Moyon ${ }^{a, *}$
}

${ }^{a}$ CNRS, Immunology, Immunopathology and Therapeutic Chemistry, UPR 3572, University of Strasbourg

${ }^{\mathrm{b}}$ Graduate School of Natural Science and Technology, Okayama University, Tsushimanaka, Kita-ku, Okayama, 700-8530, Japan

${ }^{\mathrm{c}}$ Research Core for Interdisciplinary Sciences, Okayama University, Tsushimanaka, Kita-ku, Okayama, 700-8530, Japan

a.bianco@ibmc-cnrs.unistra.fr, c.menard@ibmc-cnrs.unistra.fr

Keywords Carbon materials, Benzoquinone, Epoxide ring opening, Michael addition, Multifunctional materials

\begin{abstract}
We have developed an easy method for the double functionalization of graphene oxide (GO) using benzoquinone in mild alkaline conditions. Two functional groups were covalently linked onto GO following two separate steps: the first group was attached by an epoxide ring opening reaction while the second moiety, bearing an amine function, was covalently conjugated through a Michael addition on benzoquinone covalently bound in turn to GO. The double functionalized GO was characterized by different techniques including FT-IR and X-ray photoelectron spectroscopy, thermogravimetric analysis, cyclic voltammetry, transmission electron microscopy, and atomic force microscopy confirming the sequential covalent modification of GO surface with two different functional groups. This method is straightforward and the conditions are mild, thus allowing to preserve the structure and properties of GO. This strategy could be exploited to prepare multifunctional GO conjugates with potential applications in many fields from materials science to biomedicine.
\end{abstract}


The recent years have witnessed extensive research interests toward graphene oxide (GO) and its great potential for applications in different domains, ${ }^{[1]}$ including energy conversion and storage, ${ }^{[2]}$ electrochemical sensing, ${ }^{[3]}$ and cancer therapy. ${ }^{[4]} \mathrm{GO}$ is the oxidized form of graphene, consisting of a hexagonal ring-based carbon network with graphitic zones constituted of $\mathrm{sp}^{2}$-hybridized carbon atoms and areas with $\mathrm{sp}^{3}$-hybridized carbons formed during the oxidation process involving strong acids and oxidizing agents. ${ }^{[5]}$ The process of oxidation introduces a high amount of oxygen-containing moieties such as epoxides and hydroxyls on the basal plane of the GO sheet and, to a much lower extent, carboxylic acids and other carbonyl groups at the edges. These oxygenated functions increase the water dispersibility and enrich the chemical properties of GO. ${ }^{[6]}$ They provide reactive sites for further chemical decoration of GO allowing to extend its use for different applications such as gene therapy, ${ }^{[7]}$ drug delivery, ${ }^{[8]}$ phototherapy, ${ }^{[9]}$ biosensing, ${ }^{[10]}$ and composites. ${ }^{[11]}$ Several methods have been developed to covalently derivatize GO through the oxygenated functions on its surface, ${ }^{[12]}$ including the reaction of the carboxyl and hydroxyl groups with isocyanate derivatives, ${ }^{[13]}$ esterification of the carboxylic acids, ${ }^{[14]}$ silanization of the hydroxyls, ${ }^{[15]}$ Williamson reaction ${ }^{[14 b]}$ and Claisen rearrangement. ${ }^{[16]}$ The epoxides can be functionalized by ring opening using amine derivatives. ${ }^{[17]}$ Since this variety of different oxygenated groups is present on GO, the risk of side reactions is high. In addition, the functionalization should be performed in mild conditions because GO is not stable at high temperature and it can be thermally reduced. ${ }^{[18]}$

Beside mono-functionalization of GO, the covalent double functionalization allows to better control the specific attachment of distinct molecules or nanoparticles through different reactions. In addition, the bond between GO and the new functional groups is more stable compared to non-covalent conjugates, a generally preferred approach. Only few strategies for the covalent double functionalization of GO have been reported. One paper described amidation of $\mathrm{COOH}$ groups on carboxylated GO using a mixture of octa-arginine and amino-polyethylene glycol. ${ }^{[19]}$ This method is limited by: i) the strong basic conditions used to carboxylate GO that could reduce GO and change its properties such as water dispersibility, and ii) the concomitant amidation using a mixture of two amine derivatives, which may render this procedure difficult to control. Alternatively, a stepwise double functionalization of GO has been achieved by a double click reaction using GO bearing an azide and an alkyne moiety introduced through a combination of epoxide ring opening and Steglich esterification of the COOH groups. ${ }^{[20]}$ This method allows better controlling the conjugation of the two molecules compared to a one-pot strategy. Nevertheless, this method is limited by the low amount of carboxyl groups present on $\mathrm{GO}^{[17]}$ which may lead to low levels of functionalization. Indeed, $\mathrm{COOH}$ are localized at the edges, and 2D materials have a limited amount of edge functions compared to the basal plane containing mainly epoxides and hydroxyl groups.

Benzoquinone is widely used as coupling agent to obtain protein-protein or protein-polysaccharide conjugates. ${ }^{[21]}$ The polysaccharide or the protein is activated with benzoquinone in a mild alkaline solution and then mixed with a second biomolecule. The conjugation takes place through a Michael addition between benzoquinone and the amine or hydroxyl groups on the protein or the sugar chain. For example, nanodiamond-protein covalent complexes have been prepared using benzoquinone as crosslinker. ${ }^{[22]}$ Here, we aimed to develop a facile and efficient method to covalently double functionalize GO through the combination of an epoxide ring opening reaction and a Michael addition of the hydroxyl groups on benzoquinone. The first step consists in the opening of the epoxides by a thiol-terminated molecule, thus allowing to introduce the first functionality and to generate more hydroxyls, which subsequently reacted with benzoquinone through a Michael addition. The resulting 
GO-hydroquinone derivative was oxidized to the corresponding benzoquinone in the presence of an excess of benzoquinone during the reaction. ${ }^{[21]}$ A second molecule bearing a primary amine was covalently grafted onto the modified GO through a Michael addition between the benzoquinone moiety and the amine. All functionalized GO intermediates and final conjugates were characterized by X-ray photoelectron spectroscopy (XPS), thermogravimetric analysis (TGA), cyclic voltammetry, transmission electron microscopy (TEM), atomic force microscopy (AFM), and FT-IR spectroscopy proving unequivocally that GO was covalently double functionalized. This method is easy to perform and the reaction takes place in mild condition at room temperature without any catalyst. Therefore, this approach is also appropriate for the introduction of temperature- or $\mathrm{pH}$-sensitive functional groups that can be smoothly conjugated onto GO.

Our strategy to the double functionalized GO followed a three-step procedure illustrated in Scheme 1. Large GO flakes $(30 \mu \mathrm{m})$ were synthesized through a modified Hummers' method, and using a jet mill with a $0.1 \mathrm{~mm}$ nozzle we reached an average lateral size of $1 \mu \mathrm{m} .{ }^{[23]}$ The first step consisted on the introduction of Boc-aminoethanethiol through nucleophilic attack of the thiol group on the epoxide leading to ring opening and formation of a thioether bond and new hydroxyl groups. ${ }^{[24]}$
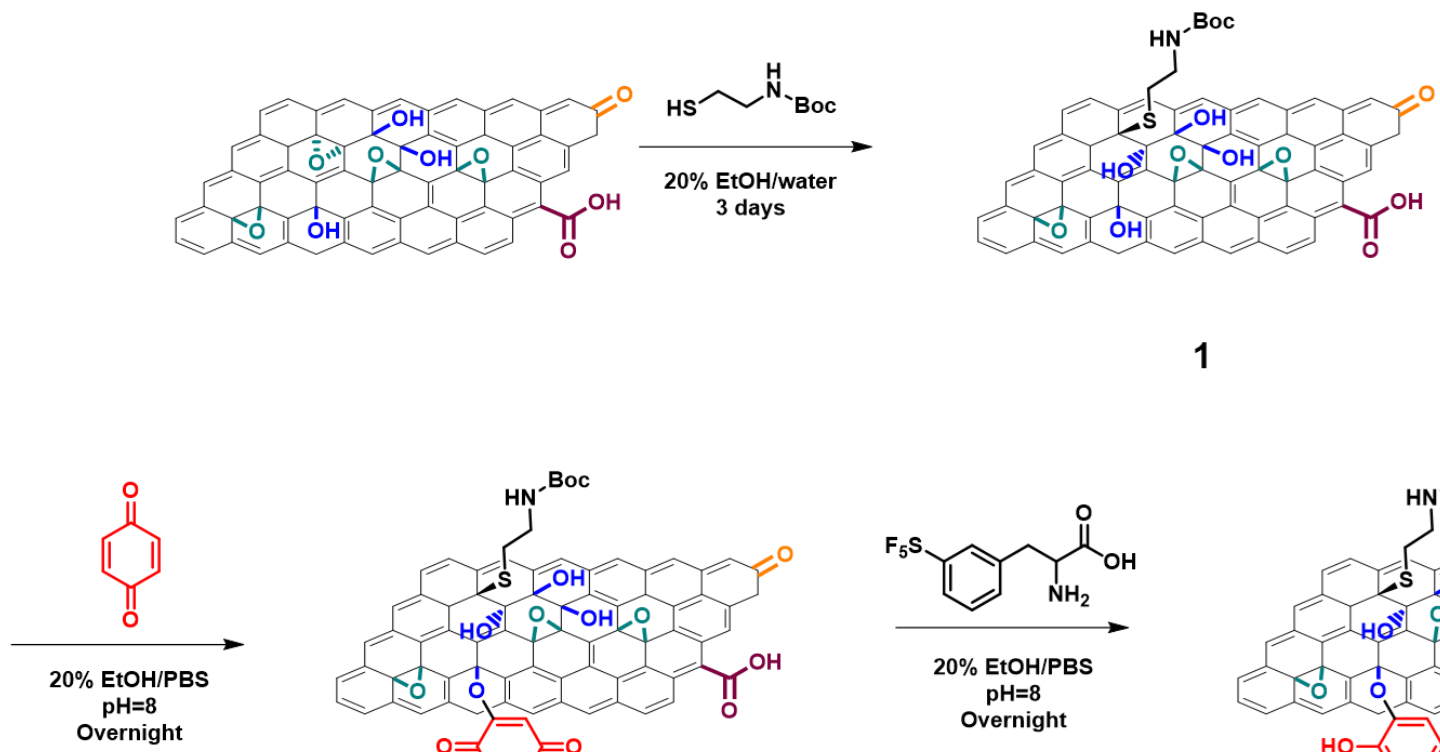

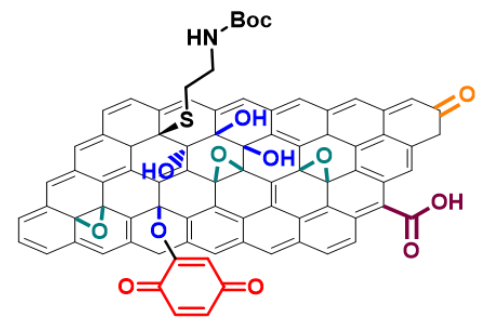

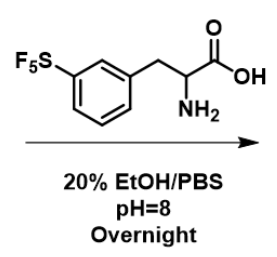

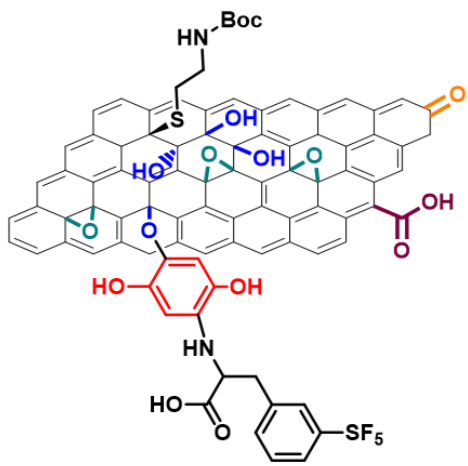

3

Scheme 1. Double functionalization of GO. For the sake of clarity, only one epoxide and one hydroxyl group are derivatized.

The mono-functionalized GO 1 was characterized by XPS (Figure 1). Compared to starting GO, the sulfur atom content increased from $0.5 \%$ to $1.4 \%$ after the first step of functionalization and the nitrogen content increased from $0.4 \%$ to $1.1 \%$, indicating the presence of Boc-aminoethanethiol on GO (Figure 1a and d). The deconvolution of the high resolution S2p peak of starting GO showed only 
one peak at $168.4 \mathrm{eV}$, which was assigned to the $\mathrm{S}-\mathrm{O}$ bond from organosulfate groups introduced onto GO surface (Figure 1c). ${ }^{[25]}$ After functionalization with Boc-aminoethanethiol, a new peak appeared at $164.0 \mathrm{eV}$, attributed to the new S-C bond thus confirming the epoxide opening (Figure 1f). ${ }^{[26]}$ The amine was deprotected through cleavage of Boc group using $2 \mathrm{M} \mathrm{HCl}$ in dioxane on an aliquot sample. The colorimetric Kaiser test confirmed the presence of free amines $(34 \mu \mathrm{mol} / \mathrm{g}),{ }^{[27]}$ giving an additional proof of successful mono-functionalization. The amines could be further functionalized with molecules of interest in mild conditions through an amidation reaction.
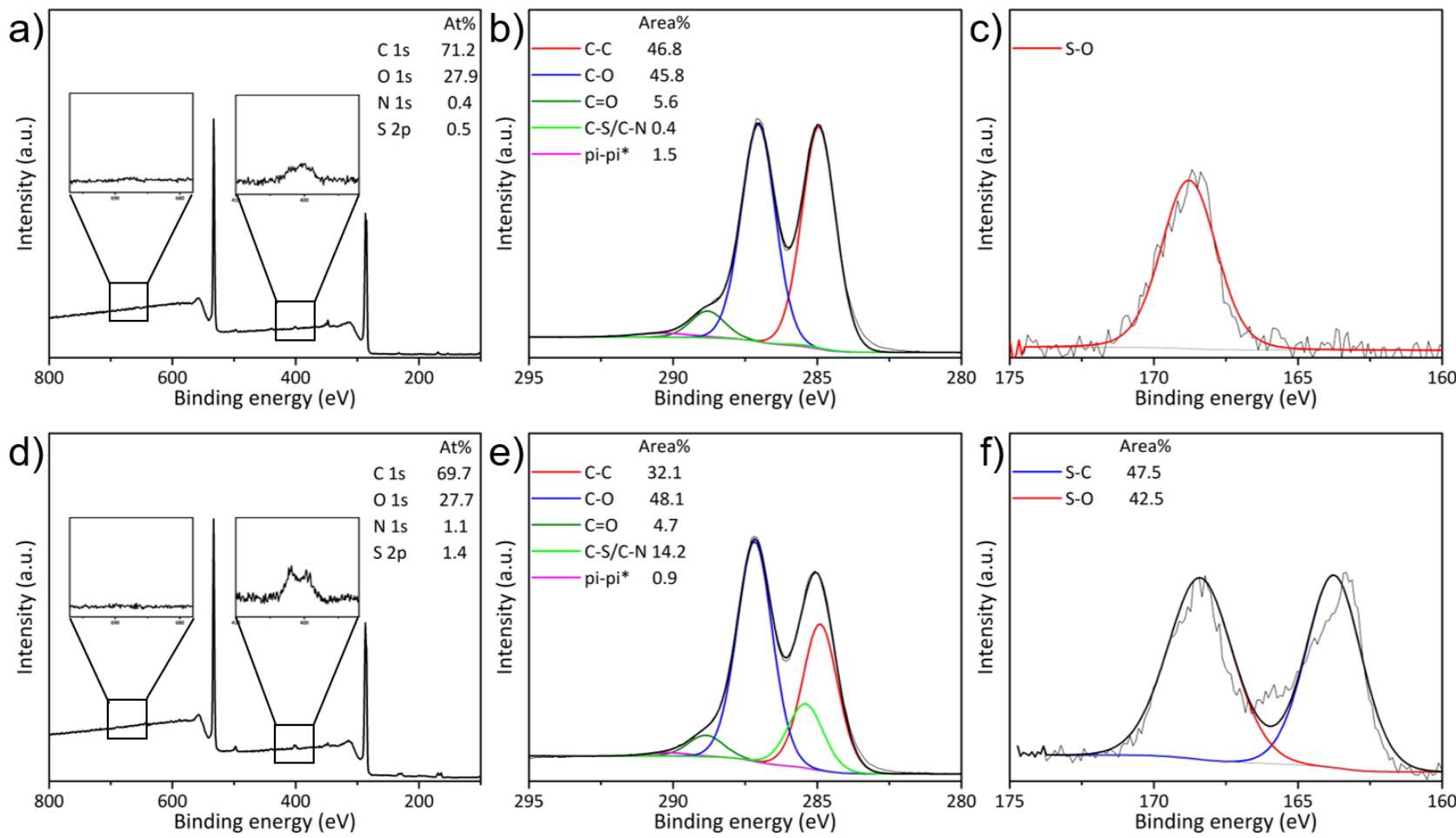

Figure 1. XPS survey spectra (a,d) with a zoom on the F1s (left inset) and N1s peaks (right inset), high resolution C1s (b, e) and S2p (c, f) spectra of GO (top row) and GO 1 (bottom row).

To perform the second step of functionalization, the hydroxyl groups of the mono-functionalized GO 1 were derivatized with benzoquinone (Scheme 1). The nucleophilic attack of the hydroxyls on benzoquinone resulted in a 2-substituted hydroquinone grafted onto GO. The hydroquinone moiety was self-oxidized by the free benzoquinone present in excess to get benzoquinone-functionalized GO 2 ready for the subsequent functionalization with amine derivatives (Scheme S1). ${ }^{[21]}$ GO 2 was characterized by XPS (Figure 2) and the area of the $\mathrm{C}-\mathrm{C}, \mathrm{C}=\mathrm{O}$, and pi-pi* peaks in the detailed analysis of the $\mathrm{C} 1 \mathrm{~s}$ spectrum increased from $32.1 \%, 4.7 \%$ and $0.9 \%$ to $51.5 \%, 6.1 \%$ and $2.9 \%$, respectively (Figure 2b), compared with GO 1 (Figure 1e). These changes could be explained by the grafting of benzoquinone onto GO, which was further used for the second functionalization. The benzoquinoneactivated GO 2 was reacted with 3-(pentafluorothio)-DL-phenylalanine giving double functionalized GO 3 (Scheme 1). We decided to choose this phenylalanine derivative because it contains a primary amine that adds on the benzoquinone moiety via a Michael addition reaction, a $\mathrm{COOH}$ function that can be further functionalized by amidation or esterification, and a pentafluorothio group that facilitates characterization by XPS and FT-IR. Fluorine atoms are often used as chemical tags for XPS as the F1s 
core-level transition has a high photoemission cross-section (four times that of carbon). ${ }^{[28]}$ The presence of fluorine was confirmed by XPS (1.6\%), while no fluorine was detected in the GO precursor conjugates (Figure 1a, 1d, 2a, and 2d). In addition, the amount of sulfur atom content increased from 0.5 to $0.7 \%$, thus confirming the introduction of the 3-(pentafluorothio)-phenylalanine moiety. The detailed analysis of the S2p peak clearly showed the presence of a new peak at $173.0 \mathrm{eV}$ (Figure 2c and f). The three main peaks were deconvoluted into three peaks at $164.5 \mathrm{eV}(\mathrm{S}-\mathrm{C}), 168.0 \mathrm{eV}(\mathrm{S}-\mathrm{O})$, and $173.0(\mathrm{~S}-\mathrm{F}) .{ }^{[24]}$ As mentioned before, the S-O peak came from the organosulfates introduced during the preparation of GO and the C-S-C peak belongs to the Boc-cysteamine. The appearance of the S-F peak was indicative of a successful double functionalization onto GO. A control reaction was performed by directly mixing GO 1 with 3-(pentafluorothio)-phenylalanine, leading to conjugate GO 3-CTR (Scheme S2). The fluorine element was $0.5 \%$ and the S-F peak in S2p spectrum was less intense than GO 3 (Figure S1), which indicates a low tendency of the phenylalanine derivative to adsorb onto GO, thus confirming the covalent linkage in the case of GO 3.
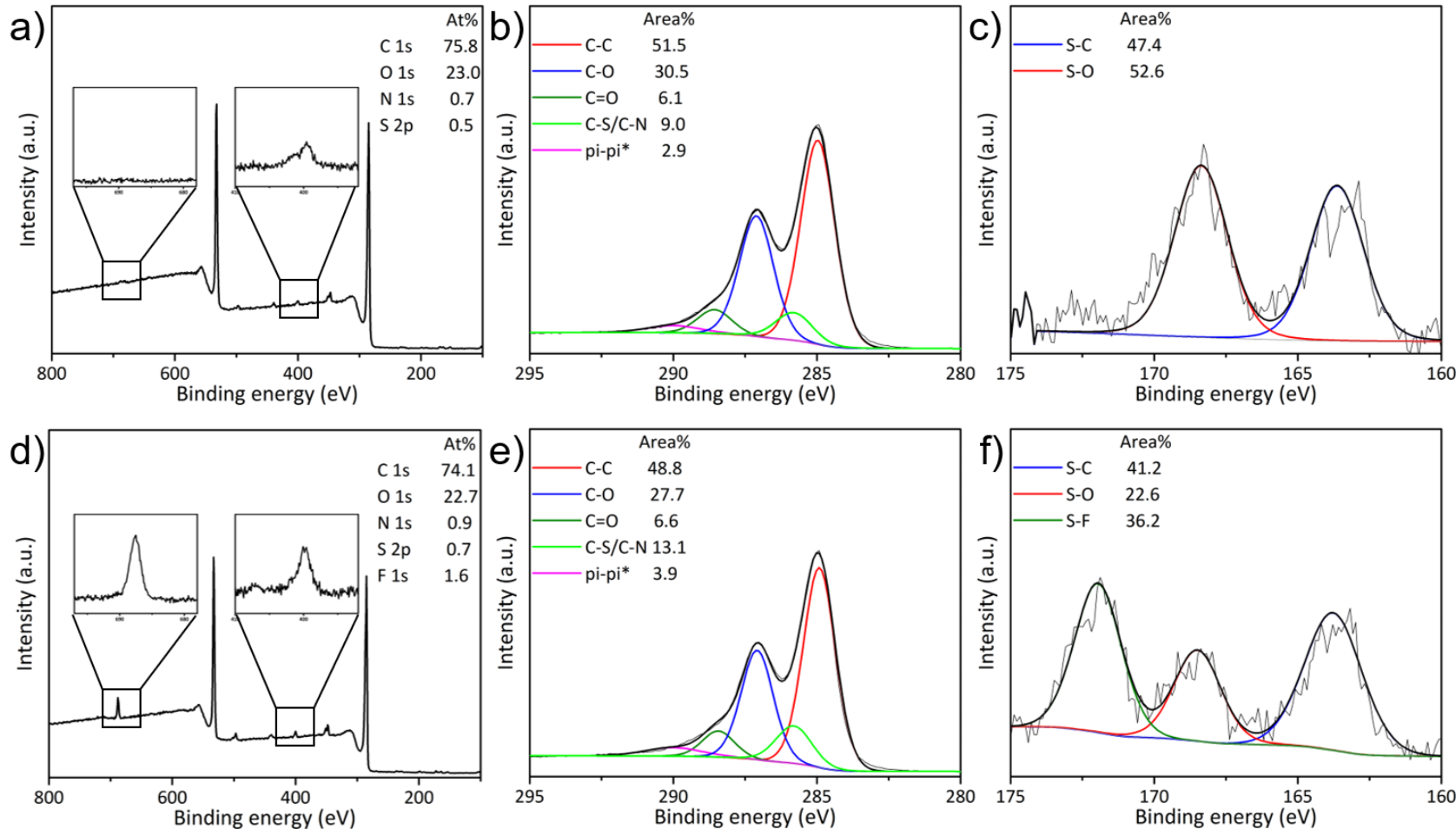

Figure 2. XPS survey spectra (a,d) with a zoom on the F1s (left inset) and N1s peaks (right inset), high resolution C1s (b, e) and S2p (c, f) spectra of GO 2 (top row) and GO 3 (bottom row).

We performed additional characterizations of the different GO conjugates using complementary analytical and microscopic techniques. Attenuated total reflectance (ATR) FT-IR spectroscopy also confirmed the double functionalization of GO (Figure 3a). A broad band centred at $\sim 3400 \mathrm{~cm}^{-1} \mathrm{can}_{\text {be }}$ assigned to $\mathrm{O}-\mathrm{H}$ stretching vibrations of adsorbed water and hydroxyl functions of $\mathrm{GO}$ and a band at $1620 \mathrm{~cm}^{-1}$ is ascribed mainly to $\mathrm{H}-\mathrm{O}-\mathrm{H}$ bending vibrations of water molecules and skeletal vibrations of unoxidized graphitic domains. ${ }^{[29]}$ The $\mathrm{C}-\mathrm{O}-\mathrm{C}$ vibration band of epoxides (at $1232 \mathrm{~cm}^{-1}$ ) is small and covered by other unassigned bands. The band at $1371 \mathrm{~cm}^{-1}$ is assigned to the bending vibration of the O-H groups of GO. New bands appeared at 2850-2970 $\mathrm{cm}^{-1}$ in GO 1 and GO 3 spectra, which 
correspond to the stretching bands of alkyl groups of the Boc-cysteamine moiety and 3(pentafluorothio)-phenylalanine. ${ }^{[17,30]}$ The appearance of a strong band at $842 \mathrm{~cm}^{-1}$ can be attributed to the characteristic S-F stretching from 3-(pentafluorothio)-phenylalanine. ${ }^{[31]}$ In the control sample GO 3-CTR, the peak at $842 \mathrm{~cm}^{-1}$ was almost negligible compared to GO 3, confirming the very low amount of phenylalanine derivative adsorbed onto GO. FT-IR characterization further confirmed the covalent grafting of 3-(pentafluorothio)-phenylalanine on GO through benzoquinone-related Michael addition.

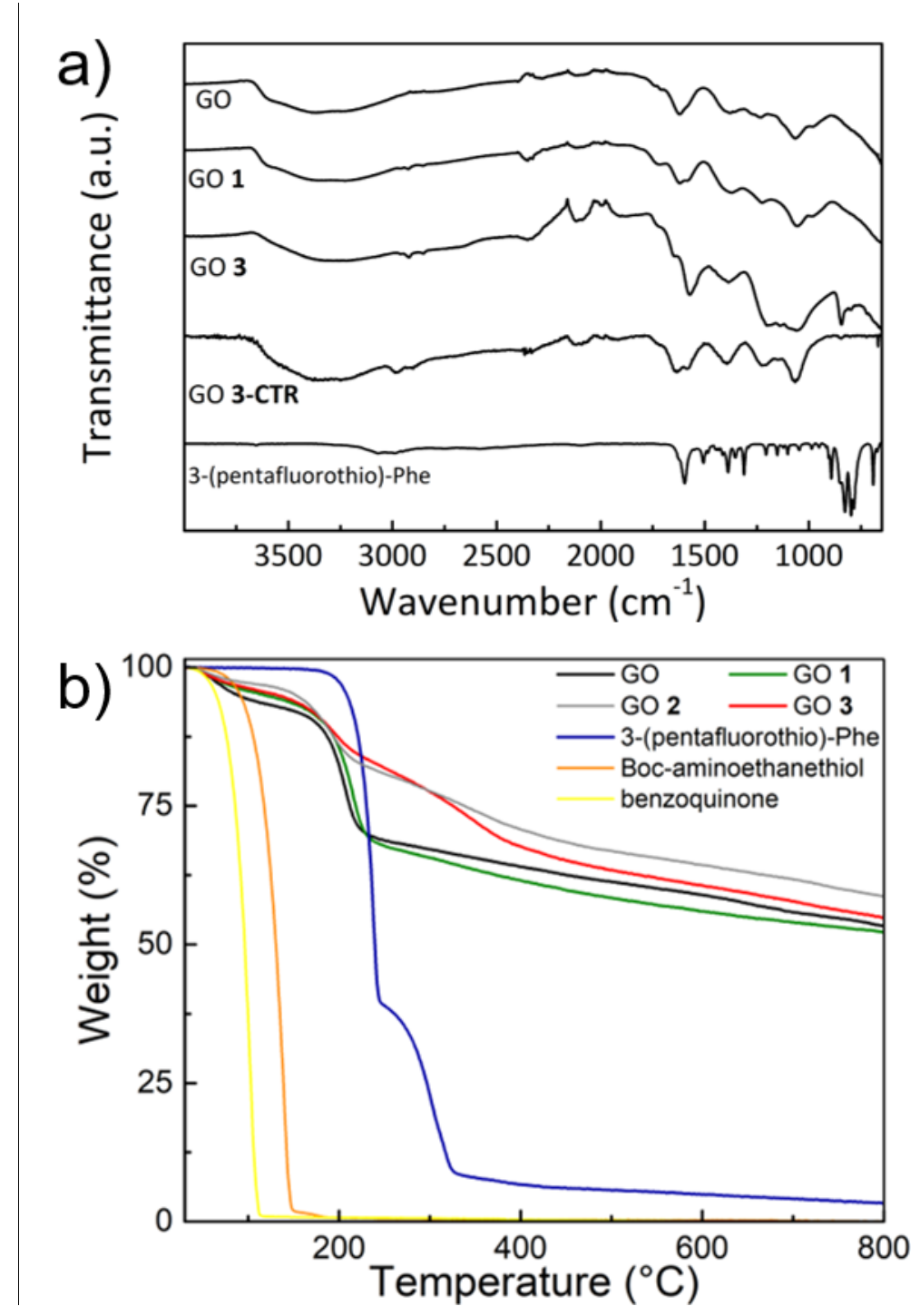

Figure 3. (a) FT-IR spectra of GO, GO 1, GO 3, GO 3-CTR, and 3-(pentafluorothio)-phenylalanine and (b) TGA of GO, GO 1, GO 2, GO 3, 3-(pentafluorothio)-phenylalanine, Boc-aminoethanethiol, and benzoquinone.

Next, we performed TGA of GO before and after functionalization in inert atmosphere at a heating rate of $10^{\circ} \mathrm{C} \cdot \mathrm{min}^{-1}$ (Figure $3 \mathrm{~b}$ ). The weight loss below $100^{\circ} \mathrm{C}$ was attributed to the desorption of water adsorbed onto GO surface. ${ }^{[17]}$ Compared to the starting GO, the functionalized GO 1, GO 2, and GO 3 presented a slightly lower weight loss below $100^{\circ} \mathrm{C}$. This could be due to the effect of the covalent functionalization. The first main weight loss for starting GO takes place at around $200^{\circ} \mathrm{C}$ and is caused 
by the removal of labile oxygenated functional groups. The gradual weight loss above $250^{\circ} \mathrm{C}$ can be ascribed to the decomposition of more stable oxygen-containing groups. The higher weight loss observed for GO 1 compared to GO can be explained by the presence of Boc-aminoethanethiol. GO 3 showed a second main weight loss at the temperature between $200^{\circ} \mathrm{C}$ and $400^{\circ} \mathrm{C}$. This could be attributed to the loss of covalently grafted 3-(pentafluorothio)-phenylalanine. The main thermal decomposition of 3-(pentafluorothio)-phenylalanine occurred at $233^{\circ} \mathrm{C}$ followed by a secondary weight loss at $300^{\circ} \mathrm{C}$. The lower weight loss observed both in GO 2 and GO 3 at $200^{\circ} \mathrm{C}$ in comparison to GO and GO 1, most probably due to a much lower amount of labile oxygenated groups such as hydroxyls because of the derivatization of the $\mathrm{OH}$ groups with benzoquinone. The weight loss difference between GO 2 and GO 3 at high temperature is indicative of the presence of 3(pentafluorothio)-phenylalanine. Overall, the TGA results confirmed the successful double functionalization of GO with two different molecules having distinct thermal properties.

The presence of quinone moiety on GO was confirmed by analyzing the electrochemical redox behavior of GO, benzoquinone, GO 2, and GO 3 (Figure 4). Pristine GO is highly dispersible in the electrolyte and it was easily leached out from the glassy carbon electrode in the electrolyte solution. Therefore, to partially reduce hydrophilicity we used slightly dehydrated GO by refluxing GO in water for $1 \mathrm{~h}$ for comparison. Thermally treated GO showed no clear redox peak (Figure 4a). Benzoquinone showed oxidation at $0.53 \mathrm{~V}$ and reduction at $0.48 \mathrm{~V}$ (Figure 4b). Similarly, GO 2 and GO 3 showed oxidation (at 0.52 and $0.51 \mathrm{~V}$ ) and reduction (at 0.45 and $0.44 \mathrm{~V}$ ) peaks, respectively (Figure $4 \mathrm{c}$ and d), suggesting successful functionalization of GO with benzoquinone.

(a)

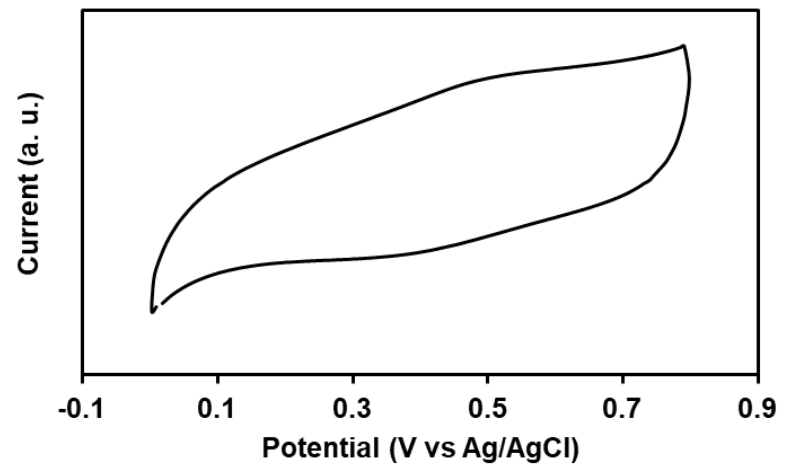

(c)

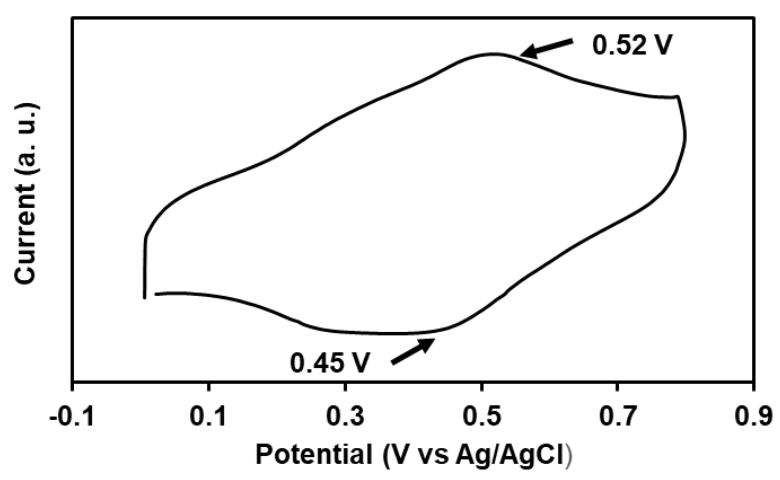

(b)

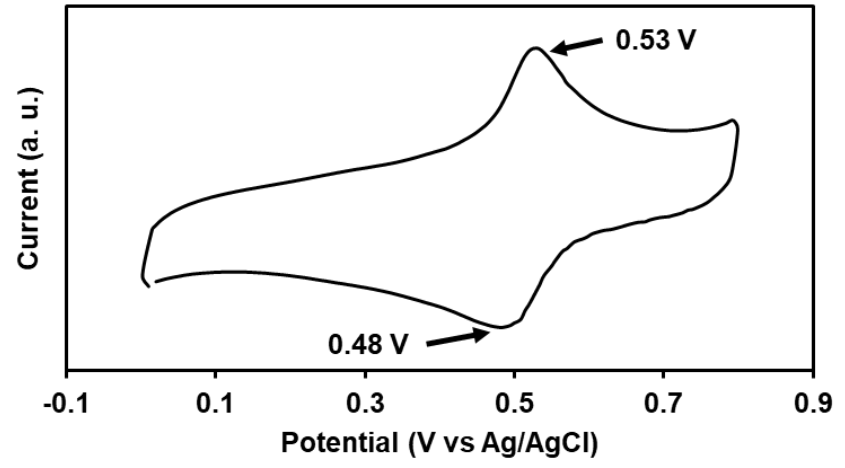

(d)

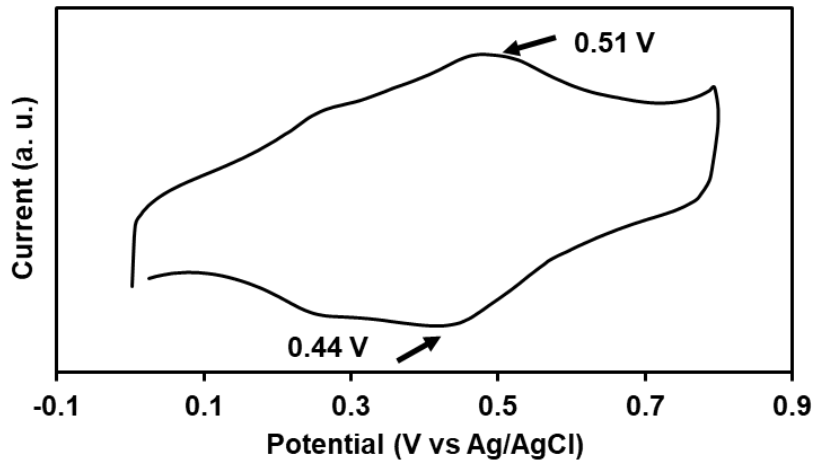

Figure 4. Cyclic voltammogram of (a) GO, (b) benzoquinone, (c) 2, and (d) 3. Scan rate: $50 \mathrm{mV} \cdot \mathrm{s}^{-1}$, Electrolyte: $0.5 \mathrm{M} \mathrm{H}_{2} \mathrm{SO}_{4}$. 
Finally, the characterization by TEM and AFM showed that the morphology of the GO sheets was preserved after the double functionalization process (Figure S2 and S3). Indeed, both starting GO and GO 3 have wrinkled sheets with folded edges with a similar lateral size dimension. AFM showed an increase of the thickness from 0.8 to $1.2 \mathrm{~nm}$ due to functionalization. Hence, the epoxide ring opening reaction and the Michael addition did not affect the morphology of GO, while increasing the thickness. In summary, we developed a simple method for the double functionalization of GO in mild conditions by successive derivatization of the epoxides and hydroxyl groups. The first step was achieved by nucleophilic opening of the epoxides with a thiol-containing molecule. The mono-functionalized GO, containing more $\mathrm{OH}$ groups compared to pristine $\mathrm{GO}$, was modified with benzoquinone, which is very reactive toward nucleophiles. Finally, 3-(pentafluorothio)-phenylalanine was added to GObenzoquinone through a Michael addition between the amine and the benzoquinone. The covalent functionalization of GO was confirmed by XPS, FT-IR, TGA, cyclic voltammetry, TEM, and AFM. Using this simple and robust approach, GO was efficiently functionalized with two different functional groups by exploiting the epoxides and hydroxyls that are present in large amount on the basal plane of the material. The Boc group on GO can be easily removed and the corresponding amine can be further derivatized with biologically active molecules though amidation for instance. Our strategy is especially appropriate for the conjugation of biomolecules and it could be exploited for modifying GO with drugs, peptides, proteins, or aptamers, to obtain multifunctional GO for applications in therapy, biosensing, and bioimaging. Compared with other covalent multi-functionalization protocols, the benzoquinonebased method is performed in mild conditions without heating or without adding metal catalysts. In addition to amines, benzoquinone can also react with azides, phosphines, and thiol groups through Michael addition and with cyclopentadienes via Diels-Alder reaction, further expanding the versatility and the flexibility to our approach. ${ }^{[32]}$ The morphology of the sheets is preserved and the functionalization does not cause reduction of GO. Temperature- and $\mathrm{pH}$-sensitive functional groups could be covalently grafted, thus extending the use of GO for further research not only in biomedicine, but also in other fields.

\section{Acknowledgements}

We gratefully acknowledge the Centre National de la Recherche Scientifique (CNRS), the International Center for Frontier Research in Chemistry (icFRC), and financial support from the Agence Nationale de la Recherche (ANR) through the LabEx project Chemistry of Complex Systems (ANR-10-LABX-0026_CSC). SG is indebted to the China Scholarship Council for supporting his PhD internship. We wish to thank C. Royer and V. Demais for help with TEM analyses at the "Plateforme Imagerie in vitro" at the Center of Neurochemistry (INCI, Strasbourg, France). We also acknowledge R. Khan and S. Obata for cyclic voltammetry and AFM analyses.

\section{References}

[1] X. Yu, H. Cheng, M. Zhang, Y. Zhao, L. Qu, G. Shi, Nat. Rev. Mater. 2017, 2, 17046-17058.

[2] a) P. Zhang, Z. Li, S. Zhang, G. Shao, Energy Environ. Mater. 2018, 1, 5-12; b) V. Georgakilas, J. N. Tiwari, K. C. Kemp, J. A. Perman, A. B. Bourlinos, K. S. Kim, R. Zboril, Chem. Rev. 2016, $116,5464-5519$.

[3] J. Xu, Y. Wang, S. Hu, Microchim. Acta 2017, 184, 1-44. 
[4] D. K. Ji, C. Ménard-Moyon, A. Bianco, Adv. Drug Deliv. Rev. 2019, 138, 211-232.

[5] L. Dong, J. Yang, M. Chhowalla, K. P. Loh, Chem. Soc. Rev. 2017, 46, 7306-7316.

[6] D. R. Dreyer, S. Park, C. W. Bielawski, R. S. Ruoff, Chem. Soc. Rev. 2010, 39, 228-240.

[7] N. D. Q. Chau, G. Reina, J. Raya, I. A. Vacchi, C. Ménard-Moyon, Y. Nishina, A. Bianco, Carbon 2017, 122, 643-652.

[8] T. Yin, J. Liu, Z. Zhao, Y. Zhao, L. Dong, M. Yang, J. Zhou, M. Huo, Adv. Funct. Mater. 2017, 27, 1604620-1604631.

[9] B. P. Jiang, B. Zhou, Z. Lin, H. Liang, X. C. Shen, Chem. Eur. J. 2019, 25, 3993-4004.

[10] N. Cheeveewattanagul, E. Morales-Narváez, A.-R. H. A. Hassan, J. F. Bergua, W. Surareungchai, M. Somasundrum, A. Merkoçi, Adv. Funct. Mater. 2017, 27, 1702741-1702748.

[11]Z. Xiang, Q. Dai, J. F. Chen, L. Dai, Adv. Mater. 2016, 28, 6253-6261.

[12]S. Eigler, A. Hirsch, Angew. Chem. Int. Ed. 2014, 53, 7720-7738.

[13] S. Stankovich, R. D. Piner, S. T. Nguyen, R. S. Ruoff, Carbon 2006, 44, 3342-3347.

[14] a) M. Cano, U. Khan, T. Sainsbury, A. O’Neill, Z. Wang, I. T. McGovern, W. K. Maser, A. M. Benito, J. N. Coleman, Carbon 2013, 52, 363-371; b) I. A. Vacchi, J. Raya, A. Bianco, C. MénardMoyon, 2D Mater. 2018, 5, 035037-035047.

[15]P. Ji, W. Zhang, S. Ai, Y. Zhang, J. Liu, J. Liu, P. He, Y. Li, Nanotechnology 2019, 30, 115701115710.

[16] S. A. Sydlik, T. M. Swager, Adv. Funct. Mater. 2013, 23, 1873-1882.

[17]I. A. Vacchi, C. Spinato, J. Raya, A. Bianco, C. Ménard-Moyon, Nanoscale 2016, 8, 13714-13721.

[18]X. Gao, J. Jang, S. Nagase, J. Phys. Chem. C 2010, 114, 832-842.

[19] R. Imani, S. Prakash, H. Vali, S. Faghihi, Biomater. Sci. 2018, 6, 1636-1650.

[20] K. C. Mei, N. Rubio, P. M. Costa, H. Kafa, V. Abbate, F. Festy, S. S. Bansal, R. C. Hider, K. T. Al-Jamal, Chem. Commun. 2015, 51, 14981-14984.

[21] J. Brandt, L.-O. Andersson, J. Porath, Biochim. Biophys. Acta 1975, 386, 196-202.

[22] a) S. Suliman, Z. Xing, X. Wu, Y. Xue, T. O. Pedersen, Y. Sun, A. P. Doskeland, J. Nickel, T. Waag, H. Lygre, A. Finne-Wistrand, D. Steinmuller-Nethl, A. Krueger, K. Mustafa, J. Control. Rel. 2015, 197, 148-157; b) K. V. Purtov, A. I. Petunin, A. E. Burov, A. P. Puzyr, V. S. Bondar, Nanoscale Res. Lett. 2010, 5, 631-636.

[23] A. E. Del Rio Castillo, V. Pellegrini, A. Ansaldo, F. Ricciardella, H. Sun, L. Marasco, J. Buha, Z. Dang, L. Gagliani, E. Lago, N. Curreli, S. Gentiluomo, F. Palazon, M. Prato, R. Oropesa-Nuñez, P. S. Toth, E. Mantero, M. Crugliano, A. Gamucci, A. Tomadin, M. Polini, F. Bonaccorso, Mater. Horiz. 2018, 5, 890-904

[24]H. R. Thomas, A. J. Marsden, M. Walker, N. R. Wilson, J. P. Rourke, Angew. Chem. Int. Ed. 2014, 53, 7613-7618.

[25] S. Eigler, C. Dotzer, F. Hof, W. Bauer, A. Hirsch, Chem. Eur. J. 2013, 19, 9490-9496.

[26]Z. Wang, Y. Dong, H. Li, Z. Zhao, H. B. Wu, C. Hao, S. Liu, J. Qiu, X. W. Lou, Nat. Commun. 2014, 5, 5002-5009.

[27] a) E. Kaiser, R. L. Colescott, C. D. Bossinger, P. I. Cook, Anal. Biochem. 1970, 34, 595-598; b)

V. K. Sarin, S. B. H. Kent, J. P. Tam, R. B. Merrifield, Anal. Biochem. 1981, 117, 147-157.

[28]K. A. Wepasnick, B. A. Smith, J. L. Bitter, D. Howard Fairbrother, Anal. Bioanal. Chem. 2010, 396, 1003-1014.

[29] T. Szabó, O. Berkesi, I. Dékány, Carbon 2005, 43, 3186-3189.

[30]D. A. Jasim, C. Ménard-Moyon, D. Begin, A. Bianco, K. Kostarelos, Chem. Sci. 2015, 6, 3952- 
3964.

[31]R. Winter, P. G. Nixon, G. L. Gard, D. J. Graham, D. G. Castner, N. R. Holcomb, D. W. Grainger, Langmuir 2004, 20, 5776-5781.

[32] a) M. Curreli, C. Li, Y. Sun, B. Lei, M. A. Gundersen, M. E. Thompson, C. Zhou, J. Am. Chem. Soc. 2005, 127, 6922-6923; b) A. R. Kyvik, C. Luque-Corredera, D. Pulido, M. Royo, J. Veciana, J. Guasch, I. Ratera, J. Phys. Chem. B 2018, 122, 4481-4490. 